\title{
Nomogram and recursive partitioning analysis to predict overall survival in patients with stage IIB-III thoracic esophageal squamous cell carcinoma after esophagectomy
}

\author{
Shufei $\mathrm{Yu}^{1,4}$, Wencheng Zhang ${ }^{2}$, Wenjie $\mathrm{Ni}^{1}$, Zefen $\mathrm{Xiao}^{1}$, Xin Wang ${ }^{1}$, Zongmei \\ Zhou $^{1}$, Qinfu Feng ${ }^{1}$, Dongfu Chen ${ }^{1}$, Jun Liang ${ }^{1}$, Dekang Fang ${ }^{3}$, Yousheng Mao $^{3}$, \\ Shugeng $\mathrm{GaO}^{3}$, Yexiong $\mathrm{Li}^{1}$, Jie $\mathrm{He}^{3}$ \\ ${ }^{1}$ Department of Radiation Oncology, Cancer Institute (Hospital), Chinese Academy of Medical Sciences and Peking Union \\ Medical College, Beijing 100021, China \\ ${ }^{2}$ Department of Radiation Oncology, Tianjing Medical University Cancer Institute and Hospital, National Clinical Research \\ Center of Cancer, Tianjin 300000, China \\ ${ }^{3}$ Department of Thoracic Surgery, Cancer Institute (Hospital), Chinese Academy of Medical Sciences, Peking Union Medical \\ College, Beijing 100021, China \\ ${ }^{4}$ Department of Oncology, Beijing Chao-yang Hospital, Beijing 100000, China \\ Correspondence to: Zefen Xiao, email: xiaozefen2013@163.com \\ Keywords: esophageal carcinoma, esophagectomy, overall survival, nomogram, recursive partitioning analysis \\ Received: April 20, $2016 \quad$ Accepted: July 10, $2016 \quad$ Published: July 28, 2016
}

\section{ABSTRACT}

We have developed statistical models for predicting survival in patients with stage IIB-III thoracic esophageal squamous cell carcinoma (ESCC) and assessing the efficacy of adjuvant treatment. From a retrospective review of 3,636 patients, we created a database of 1,004 patients with stage IIB-III thoracic ESCC who underwent esophagectomy with or without postoperative radiation. Using a multivariate Cox regression model, we assessed the prognostic impact of clinical and histological factors on overall survival (OS). Logistic analysis was performed to identify factors to include in a recursive partitioning analysis (RPA) to predict 5-year OS. The nomogram was evaluated internally based on the concordance index (C-index) and a calibration plot. The median survival time in the training dataset was $\mathbf{3 0 . 9}$ months, and the 5-year survival rate was $33.9 \%$. T stage, differentiated grade, adjuvant treatment, tumor location, lymph node metastatic ratio (LNMR), and the presence of vascular carcinomatous thrombi were statistically significant predictors of 5-year OS. The C-index of the nomogram was 0.70 (95\% CI 0.67-0.73). RPA resulted in a three-class stratification: class 1 , LNMR $\leq 0.15$ with adjuvant treatment; class 2 , LNMR $\leq 0.15$ without adjuvant treatment and LNMR > 0.15 with adjuvant treatment; and class 3 , LNMR $>0.15$ without adjuvant treatment. The three classes were statistically significant for OS $(P<0.001)$. Thus, the nomogram and RPA models predicted the prognosis of stage IIB-III ESCC patients and could be used in decision-making and clinical trials.

\section{INTRODUCTION}

Esophageal carcinoma is the third most prevalent cancer and the fourth leading cause of cancer-related deaths in China [1]. Approximately 477,900 Chinese patients were diagnosed with esophageal cancer (both esophageal squamous cell carcinoma and esophageal adenocarcinoma) in 2015 and approximately 375,000 patients died from the disease. Peyre et al. [2] found that the number of involved lymph nodes was positively correlated with systemic disease (16-93\%). The 7th edition of the Union for International Cancer Control/ American Joint Cancer Committee (UICC/AJCC) included a fundamental change in the $\mathrm{N}$ classification from site-dependent to numerically based staging. The 5 -year OS ranged from $8-45 \%$ for patients with stage IIB-III esophageal carcinoma [3]. The 7th edition of the UICC/AJCC prognostic grouping $[4,5]$ did not perform as well for stage IIB-III patients as for early stage patients. Reeh et al. reported that the 7th edition TNM staging system poorly discriminated between stages IIIA and IIIB $(p=0.672)$, and stages IIIC and IV $(p=0.799)$ [6]. 
The new AJCC prognostic groupings for early stage patients include the histologic type [7], grade [8-10], and location of the tumor in addition to the TNM classification [3]. We hypothesized that an improved prognostic grouping could be achieved by including additional parameters associated with survival.

Nomograms can be used to quantify risk by incorporating factors that impact prognosis [11, 12]. By creating an intuitive graph of a statistically predictive model, a nomogram gives rise to a numerical probability of a clinical event (e.g. OS). Nomograms can generate more accurate predictions than the traditional TNM staging system [13-18]. However, few nomograms exist that can predict the long-term survival of patients with locally advanced esophageal squamous cell carcinoma (ESCC) post-esophagectomy. In this study, we aimed to build and validate a nomogram for locally advanced ESCC, which combined known clinicopathological variables, using data from the Chinese Academy of Medical Sciences.

\section{RESULTS}

Demographic and characteristics of patients are shown in Table 1 and Figure 1. The median followup in the training cohort was 67.5 months $(95 \%$ CI 64.8-70.7 months). The median survival and 5-year OS rates in the training cohort were 30.9 months $(95 \%$ CI 28.1-33.7 months) and 34.2\%, respectively. The 5 -year OS rates were $48.5 \%, 38.2 \%, 23.2 \%$, and $23.3 \%$ for patients with stage IIB, IIIA, IIIB, and IIIC disease, respectively $(p<0.001)$. However, there was no statistically significant difference between patients with stage IIIB or IIIC disease $(p=0.527)$.

\section{Nomogram model development and validation}

The results from a multivariate analysis of the training dataset are shown in Table 2. Based on these data, a nomogram was developed to predict 5-year OS (Figure 2), which incorporated adjuvant therapy, differentiated grade, the presence of vascular carcinomatous thrombi embolus, $\mathrm{T}$ stage (7th UICC stage), tumor location (6th UICC stage), and the lymph node metastatic ratio (LNMR). The predictive discrimination for 5-year survival was measured by the concordance index ( $\mathrm{C}$-index). The $\mathrm{C}$-index of the nomogram was 0.70 (95\%CI 0.67-0.73) (Figure.3), which demonstrated good accuracy in the training cohort. However, the C-index of 7th UICC staging system was 0.61 (95\% CI 0.58-0.64) (Figure 4) in the training dataset, which was lower than that of the nomogram in this cohort. We next used calibration plots to assess whether the nomogram estimated risk was in consistent with the observed risk. Indeed, calibration plots confirmed a strong correlation between the observed and predicted probability of 5-year OS for the entire cohort (Figure 5).
The significant factors for survival identified by multivariate cox regression, adjuvant therapy, differentiated grade, the presence of embolus, $\mathrm{T}$ stage (7th UICC stage), and the LNMR, were entered the model. LNMR and adjuvant therapy provided a tree with three nodes, separating patients into four classes; class $1: \mathbf{L N M R} \leq 0.15$ with adjuvant treatment; class 2 : $\mathbf{L N M R} \leq 0.15$ without adjuvant treatment; class 3 : LNMR > 0.15 with adjuvant treatment; class 4: LNMR $>0.15$ without adjuvant treatment. Differentiated grade, the presence of vascular carcinomatous thrombi embolus, T stage (7th UICC stage) did not contribute significantly in the modeling and were omitted from the tree. No statistical difference in OS was shown between class 2 and class $3(p=0.167)$, using log-rank test. Therefore, class 2 and 3 were collapsed into a single class. In the final RPA model for OS (Figure 6), class 1 was considered as low risk group (5-year OS rate $47.4 \%$ ), class 2 and 3 were considered as intermediate risk group (5-year OS rate $31.1 \%$ ) and class 4 was considered as high risk group (5-year OS rate $11.7 \%$ ). There were significant differences in OS (Figure 7) between risk groups on univariate Cox analysis (Hazard Ratio $[\mathrm{HR}]=1.753$, 95\% CI 1.558-1.973; $p<0.001)$.

\section{DISCUSSION}

The 7th edition of the AJCC TNM staging system, which was based on risk-adjusted random forest analyses of data from the Worldwide Esophageal Cancer Collaboration (13 institutions and 4,627 patients treated with primary esophagectomy alone) introduced new number-based N subgroups [19]. However, poor discrimination was observed in the Kaplan-Meier survival curves for each subgroup of patients. A previous report indicated that the 7 th edition staging system could not discriminate between stage IIA versus IIB, IIIA versus IIIB, or IIIC versus IV [3]. In our patient cohort, the 7 th edition criteria could not distinguish between stage IIIB versus IIIC ( $p=0.537)$. Thus, improvements in the prognostic model and risk group are warranted.

A robust model consisting of a nomogram that can be used to precisely estimate stage IIB-III ESCC patient survival has not been developed previously. Additionally, RPA for risk stratification, which could improve the clinical management of ESCC patients, has not been performed. Therefore, we developed a postoperative model to predict long-term survival and guide the clinical management of this patient population. The dataset was obtained from leading institution in China, which represents standard and advanced oncology care. Thus, the model is predicted to be easily generalizable.

On univariable and multivariable analyses, T stage, LNMR, adjuvant treatment, differentiated grade, and the presence of an vascular carcinomatous thrombi embolus were independent prognostic factors 
Table 1: Patients' characteristics

\begin{tabular}{|c|c|c|}
\hline Characteristics & Number of patients & $(\%)$ \\
\hline \multicolumn{3}{|l|}{ Sex } \\
\hline Male & 847 & 84.4 \\
\hline Female & 157 & 15.6 \\
\hline \multicolumn{3}{|l|}{ Age } \\
\hline$\leq 60$ & 564 & 56.2 \\
\hline$>60$ & 440 & 43.8 \\
\hline \multicolumn{3}{|l|}{ T stage(7th UICC) } \\
\hline $\mathrm{T} 1$ & 103 & 7.3 \\
\hline $\mathrm{T} 2$ & 147 & 14.6 \\
\hline T3 & 683 & 68.0 \\
\hline T4a & 101 & 10.1 \\
\hline LNMR & 20 & 2.0 \\
\hline $0-0.073$ & 395 & 39.3 \\
\hline $0.073-0.15$ & 297 & 29.6 \\
\hline$>0.15$ & 292 & 29.1 \\
\hline \multicolumn{3}{|l|}{ Tumor Location } \\
\hline Upper third & 81 & 8.1 \\
\hline Middle third & 471 & 46.9 \\
\hline Lower third & 452 & 45.0 \\
\hline \multicolumn{3}{|l|}{ Treatment } \\
\hline Surgery & 490 & 48.8 \\
\hline Surgery + adjuvant & 514 & 51.2 \\
\hline
\end{tabular}

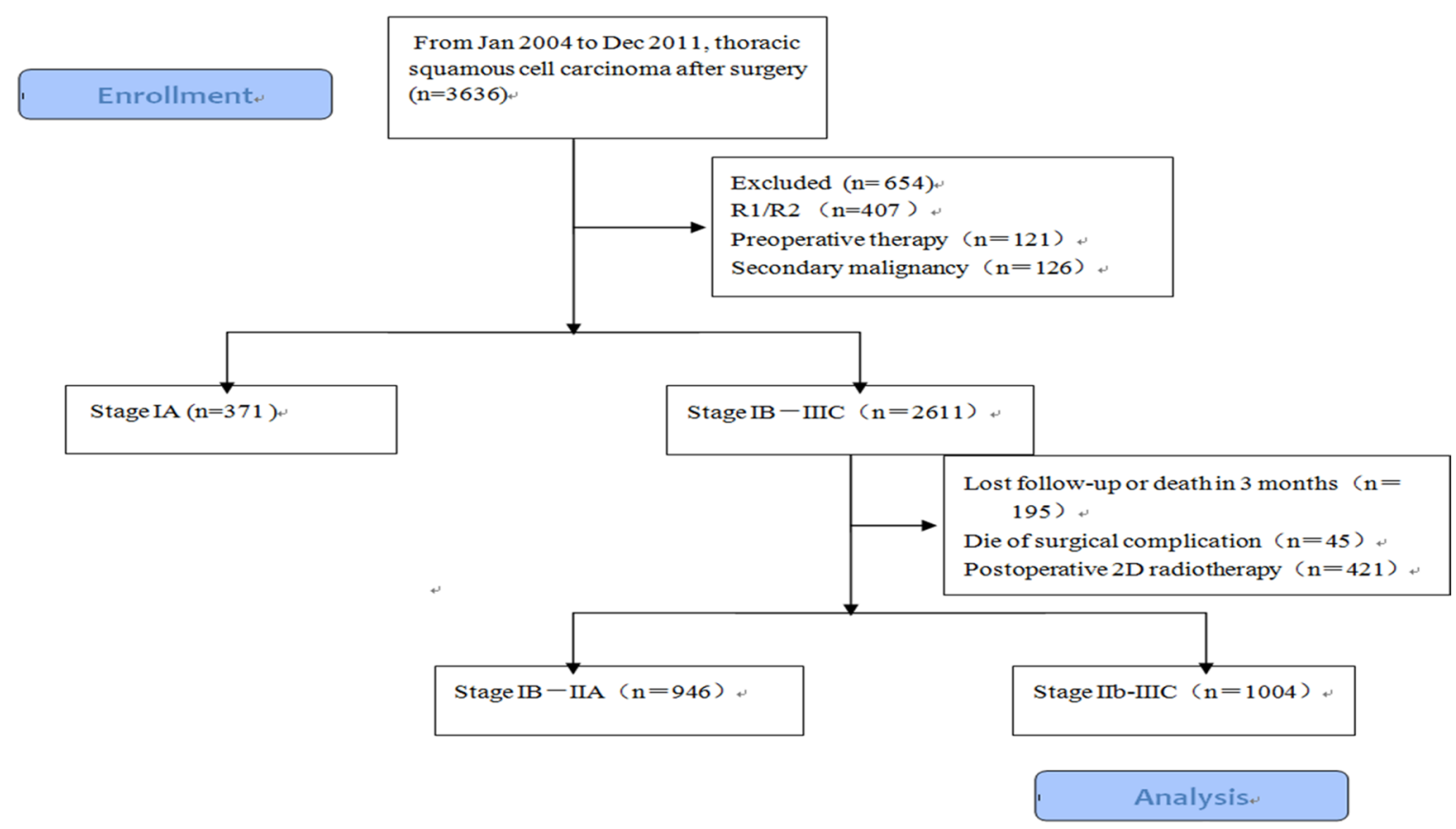

Figure 1: Flow diagram of the patients received radical surgery in Chinese Academy of Medical Sciences, 1004 patients in stage IIb-III were enrolled. 
Table 2: Multivariate analysis of patients in primary cohort

\begin{tabular}{|c|c|c|c|}
\hline Variables & HR & $95 \% \mathrm{CI}$ & $P$ \\
\hline Grade & & & 0.045 \\
\hline High & Ref. & & \\
\hline Moderate & 1.065 & $0.826-1.374$ & 0.625 \\
\hline Low & 1.291 & $0.989-1.685$ & 0.061 \\
\hline Embolus & & & 0.004 \\
\hline Absent & Ref. & & \\
\hline Present & 1.329 & $1.094-1.602$ & 0.004 \\
\hline Tumor site & & & 0.087 \\
\hline Upper third & Ref. & & \\
\hline Mid third & 0.868 & $0.652-1.156$ & 0.033 \\
\hline Lower third & 0.755 & $0.564-1.011$ & 0.059 \\
\hline LNMR & & & 0.000 \\
\hline 0 & Ref. & & \\
\hline $0-0.073$ & 1.948 & $0.928-4.092$ & 0.078 \\
\hline $0.074-0.15$ & 2.513 & $1.192-5.195$ & 0.015 \\
\hline$>0.15$ & 3.773 & $1.795-7.933$ & 0.000 \\
\hline T stage & & & 0.000 \\
\hline $\mathrm{T} 1$ & Ref & & \\
\hline $\mathrm{T} 2$ & 1.334 & $0.899-1.980$ & 0.152 \\
\hline $\mathrm{T} 3$ & 1.931 & $1.365-2.731$ & 0.000 \\
\hline $\mathrm{T} 4$ & 2.013 & $1.307-3.101$ & 0.001 \\
\hline Treatment & & & 0.000 \\
\hline Surgery & Ref. & & \\
\hline Surgery + adjuvant & 0.615 & $0.523-0.722$ & 0.000 \\
\hline
\end{tabular}

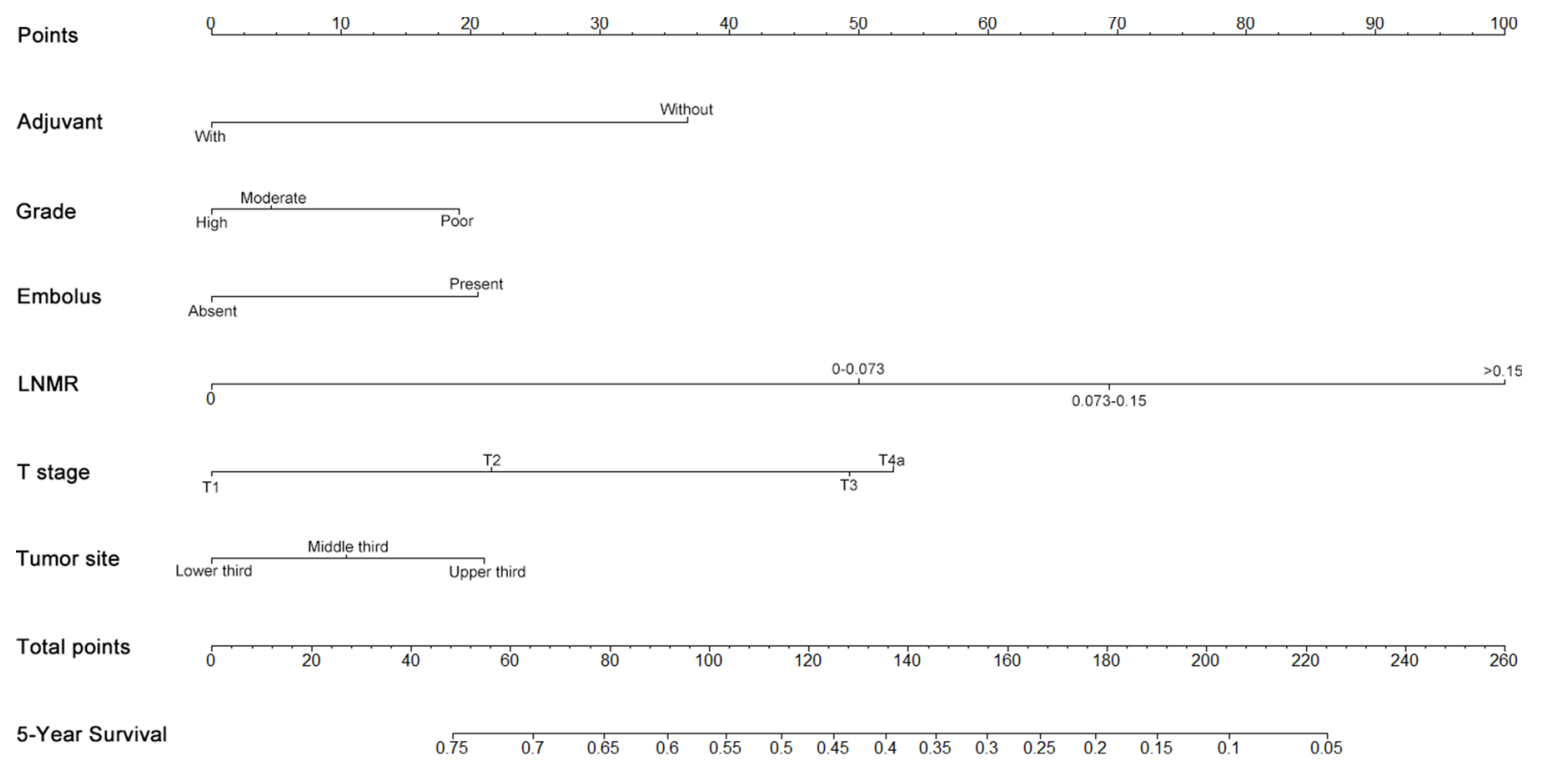

Figure 2: Nomogram to predict 5-year survival in patients with stage IIb-III ESCC. To use the nomogram, the value attributed to an individual patient is located on each variable, and a line is then drawn downwards to the survival axis to determine the 5-year OS likehood. 


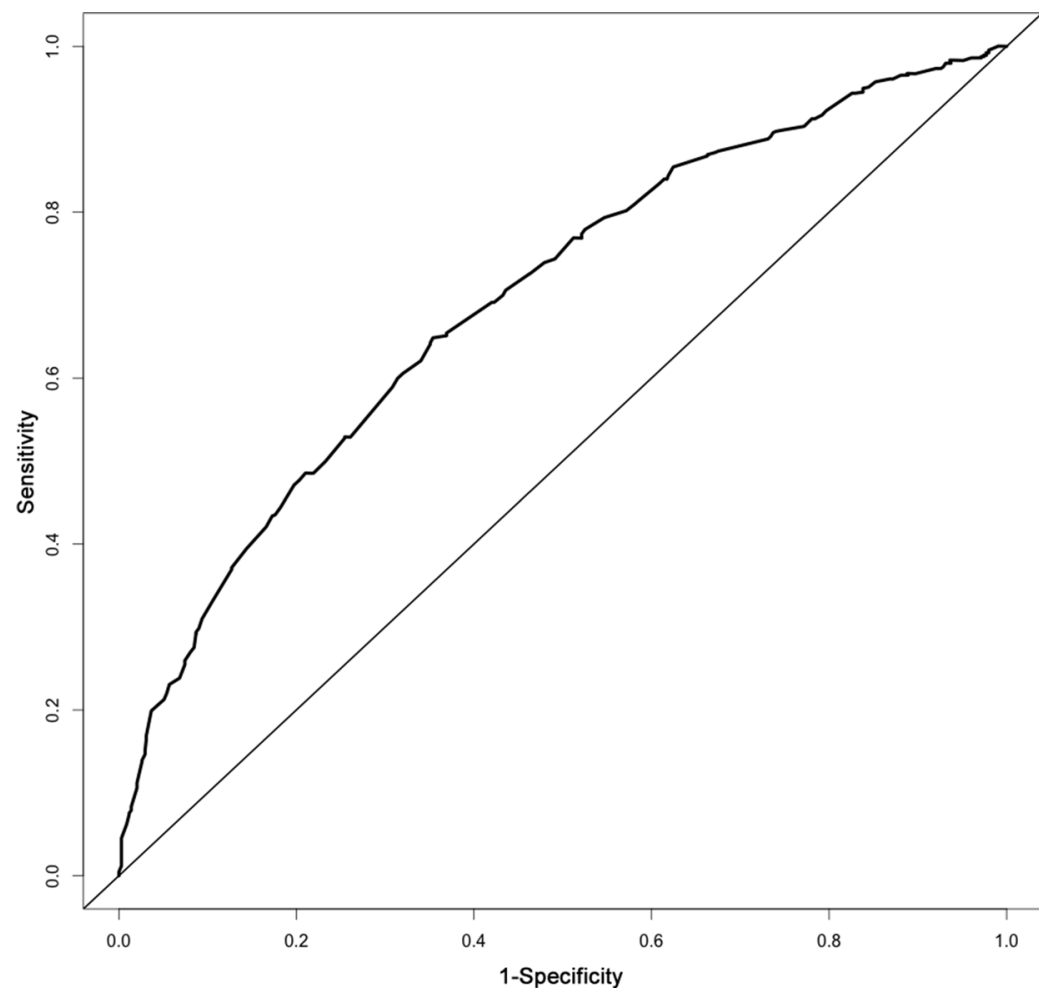

Figure 3: The area under the receiver operating characteristic (ROC) curve of the nomogram for stage IIb-III ESCC was 0.70 .

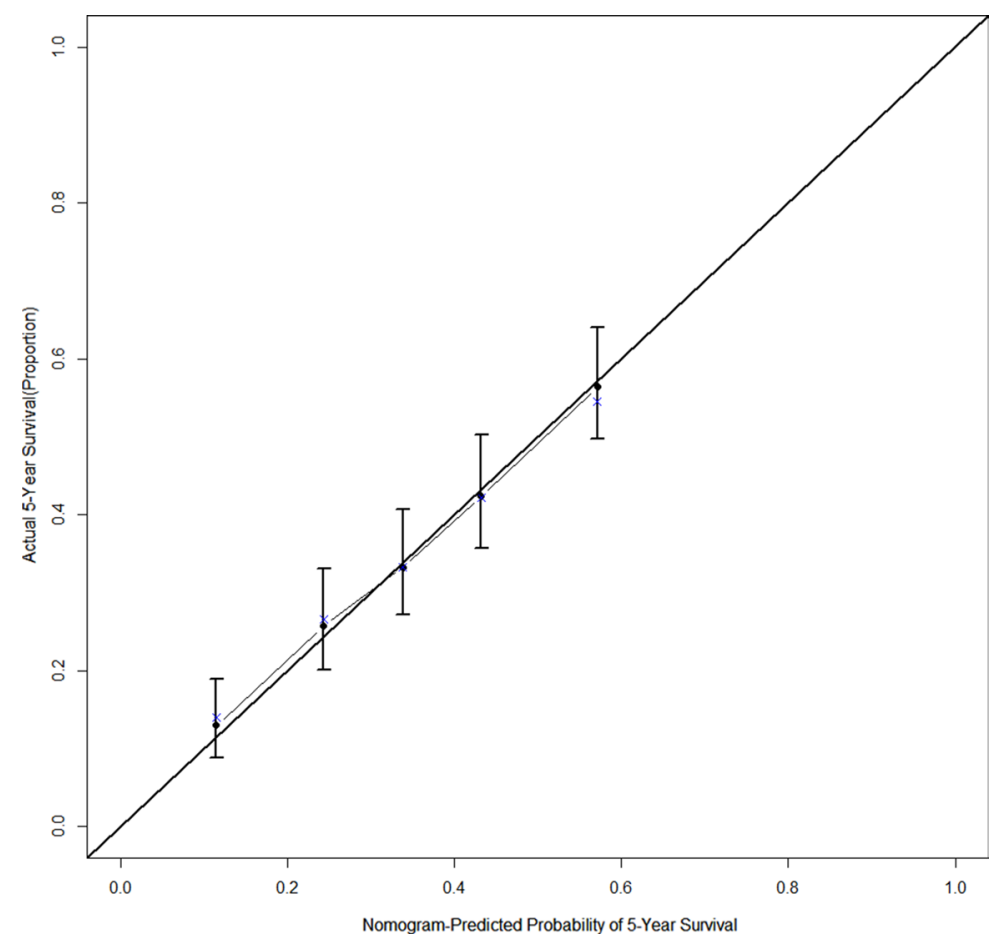

Figure 4: The calibration curve for predicting 5-year survival after esophagectomy in stage IIb-III thoracic ESCC patients, the nomogram-predicted probability of OS is plotted on the $x$ axis; the actual observed OS is plotted on the y axis. 


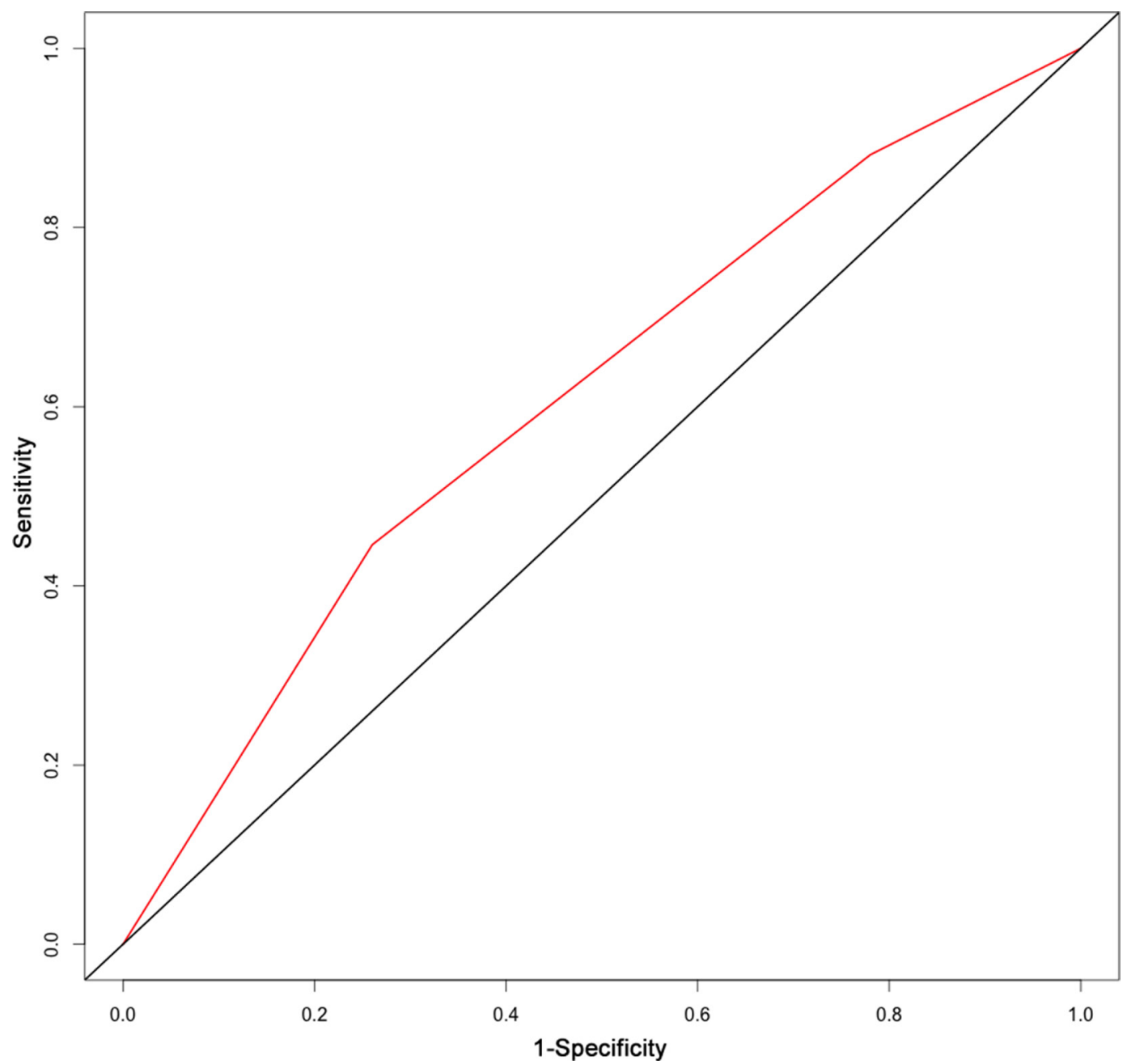

Figure 5: The area under the receiver operating characteristic (ROC) curve of 7th UICC staging system for stage IIb-III ESCC was 0.61.

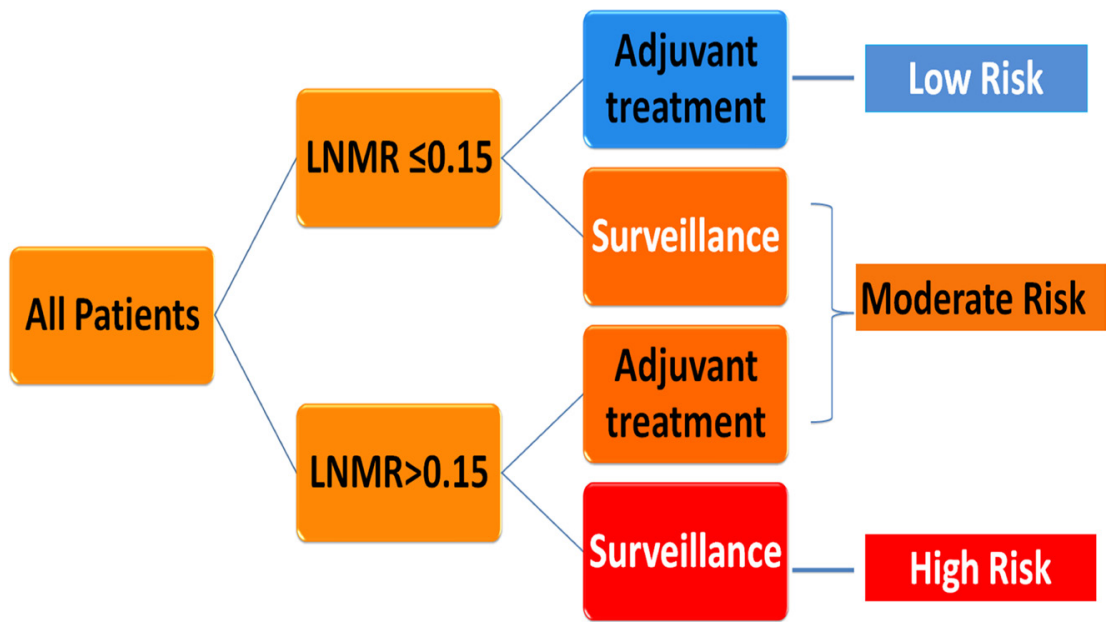

Figure 6: Decision tree constructed by recursive partitioning analysis for patients with stage IIb-III ESCC. 
for ESCC. Differentiated grade and tumor location are considered prognostic factors for early-stage ESCC in the AJCC staging system [20], but not for locally advanced disease. Here, we defined tumor location based on the 6th edition of the UICC staging system [21] and incorporated it into the model. Tumor location was documented during surgery for most patients. Previous studies have demonstrated that the $\mathrm{N}$ group was a good prognostic factor for survival [2, 22-32]. Lymphatic metastasis in esophageal carcinoma is widespread dissemination from lower cervical and supraclavicular region to the celiac lymph node basins. Number of harvested lymph nodes may associate with the longer survival for the probabilities of missing a positive lymph node and erroneously classified with an earlier stage cancer decrease. Currently, there is no international consensus as to the minimum number of lymph nodes that should be examined. It has been proposed that at least 12 lymph nodes be removed for pathological analysis [22]. Peyre et al. [32] reported that the removal of more than 23 lymph nodes was a favorable prognostic factor. However, Altorki et al. [33] found that the removal of 16-30 lymph nodes in two-field lymphadenectomy did not improve survival. Both Schwarz et al. [34] and Groth et al. [35] suggested that more than 30 lymph nodes should be removed during radical surgery for esophageal carcinoma, which was based on an analysis of a large number of samples. In the present study, we hypothesized that the LNMR (the ratio of positive nodes and removed lymph nodes) could accurately predict survival in both adequately and inadequately staged patients. LNMR varies based on the segment of the esophagus that is involved and may be correlated with the operative approach, range, and number of lymph nodes examined. The LNMR has been suggested as an important prognostic factor in many cancers [33, 36-44]. Using ROC curve, we determined that a LNMR of 0.073 was the optimal cut-off point, which resulted in a maximum Youden's index value. To make the distribution of patients among the groups balanced, a second cut-off value was 0.150 . Adjuvant treatment was also incorporated into the model because subgroup analyses of prospective randomized clinical trials as well as retrospective analyses have indicated that it can improve OS [45-55]. The predictive accuracy of the nomogram increased when non-TNM factors were included. The RPA-based risk group was distinctive for each group in the training dataset $(p<0.001)$.

Validation of the nomogram was essential to avoid over-fitting of the model and determine generalizability. In this study, calibration plots showed optimal agreement between predictions and actual observations, which provided evidence for the repeatability and reliability of the nomogram. Discrimination of the nomogram was revealed by the higher $\mathrm{C}$-index of the nomogram compared to the TNM staging system (C-index 0.61$)$ in the training cohort. We found that the 7 th edition AJCC staging system was not distinctive for stage IIIB versus IIIC in the training dataset $(p=0.537)$.

To the best of our knowledge, this is the first nomogram and RPA model for predicting the survival of locally advanced ESCC patients based on a large sample size and a long-term follow-up. Both physicians and patients could perform an individualized survival prediction after radical surgery through this easy-to-use scoring system. The identification of subgroups of patients at different risks for poor survival might impact treatment. We believe that the established nomogram and RPA models are more accurate prognostic models that the TNM staging system. Nonetheless, the models are limited by the

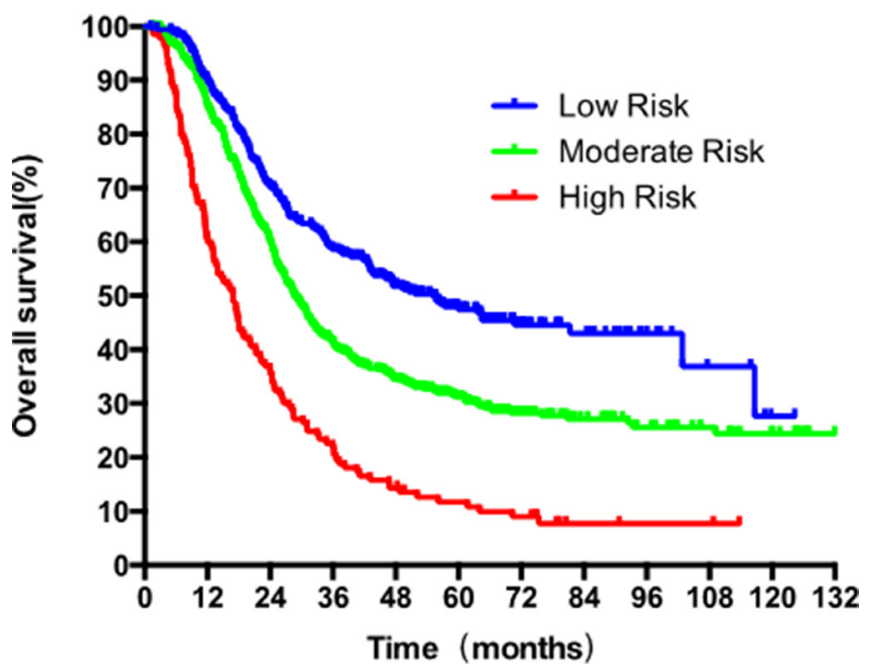

Figure 7: Survival analysis with Kaplan-Meier plot based on the three risk categories generated by recursive partitioning analysis for 5-year OS. 
retrospective nature of the data collection, which prevented the incorporation of several commonly recognized prognostic parameters (e.g. EGFR expression [56] and the circumferential resection margin [57]).

External validation is required for this model. Additional prospective studies including patients with planned follow-up, as well as the incorporation of several other factors are necessary to improve the model.

In conclusion, we have established and validated a novel model using a nomogram and RPA to predict ESCC patient survival and to stratify patients into different risk groups. This model can be used to make treatment decisions in patients with ESCC.

\section{MATERIALS AND METHODS}

\section{Patient characteristics}

We performed a retrospective review of a cohort consisting of 3,636 patients who were diagnosed with thoracic ESCC and underwent esophagectomy between January 1, 2004 and December 31, 2011 at the Chinese Academy of Medical Sciences (Figure. 1). All patients were restaged based on the 7 th edition of the UICC/AJCC staging system. Patients who underwent radical surgery and were pathologically diagnosed with stage IIB-III disease were enrolled in the study. The exclusion criteria were the following: 1) preoperative treatment; 2) inadequate follow-up data; 3) pathological type other than squamous cell carcinoma; 4) diagnosis of a malignancy other than esophageal carcinoma. The remaining 1,004 patients comprised the training dataset (Table 1). All patients underwent radical esophagectomy (R0) with two- or threefield lymphadenectomy. There were 514 patients $(51.0 \%)$ who did not receive any postoperative treatment and 490 $(49.0 \%)$ who did receive adjuvant treatment. A total of 56 patients $(5.6 \%)$ received adjuvant chemotherapy, 323 $(32.2 \%)$ received adjuvant radiotherapy, and 135 (13.4\%) received both chemotherapy and radiotherapy. Adjuvant therapy was initiated 4-6 weeks after surgery. Patients received either a taxane- or fluorouracil-based regimen. Radiotherapy was administered at a total dose of 50-60 Gy (1.8-2.0 Gy per fraction). This project was approved by our Institutional Review Board and conducted in accordance with the Declaration of Helsinki.

\section{Nomogram construction and recursive partitioning analysis}

Factors anticipated to influence survival and variables that retained independent statistical significance in multivariate analyses were introduced into the nomogram. Variables that achieved significance at $p<0.1$ in univariate analyses were incorporated into the multivariable analyses through a Cox regression model. Selection of the final model was performed using a backward step-down process. Nomogram validation included: 1) internal validation, in which the Harrell's C-index [58] was estimated by analyzing the area under the curve (AUC) of the receiver operating characteristic (ROC) curve to obtain an unbiased measure of the ability of the nomogram to discriminate between patients. The C-index ranged from $0.5-1.0$, where 0.5 was indicative of random chance and 1.0 was indicative of perfect discrimination of the outcome using the model; 2) calibration, which was performed in order to examine how well the model-based predicted probability of survival agreed with the observed probabilities (in this calculation, 200 bootstrap resamples were used to generate the $95 \%$ CIs for the plot). Statistical analyses to identify independent prognostic factors were conducted using SPSS 20.0 for Windows (SPSS, Chicago, IL, USA). Based on the results of the multivariable analysis, a nomogram was formulated using the R software (http://www.r-project.org) with the survival ROC,Hmisc, and rms packages.

RPA provides a simple way to group patients into different categories. RPA divided patients at each step into two groups based on the covariate that provided maximum separation with respect to prognosis and accounted for interactions between factors [59]. This analysis was performed using the training dataset to predict the primary endpoint based on an inventory of eight factors. The $\mathrm{R}$ software with the rpart package was used for the analysis, where a minimum of 20 observations was required to split a node. This was followed by trimming of less important downstream branches. A minimum of 10 observations (default) was required for a terminal node. The clinical utility was enhanced by rounding the cut-off points to the nearest significant digit. The OS rates were compared between the RPA risk groups using log-rank tests. The primary endpoint was survival at the end of the 5-year period, which was calculated from the date of surgery to the date of either the last follow-up or death using the KaplanMeier method. Follow-up was calculated using the reverse Kaplan-Meier method. Patients who were alive as of November 10, 2015 were censored as of that date.

\section{ACKNOWLEDGMENTS}

None.

\section{CONFLICTS OF INTEREST}

The authors declare that there are no conflicts of interest. The authors alone are responsible for the content and writing of the paper.

\section{FUNDING}

The capital health research and development of special 2016-2-4021. 


\section{REFERENCES}

1. Chen W, Zheng R, Baade PD, Zhang S, Zeng H, Bray F, Jemal A, Yu XQ, He J. Cancer statistics in China, 2015. CA Cancer J Clin. 2016; 66:115-132.

2. Peyre CG, Hagen JA, DeMeester SR, Van Lanschot JJ, Holscher A, Law S, Ruol A, Ancona E, Griffin SM, Altorki NK, Rice TW, Wong J, Lerut T, et al. Predicting systemic disease in patients with esophageal cancer after esophagectomy: a multinational study on the significance of the number of involved lymph nodes. Annals of surgery. 2008; 248:979-985.

3. Gertler R, Stein HJ, Langer R, Nettelmann M, Schuster T, Hoefler H, Siewert JR, Feith M. Long-term outcome of 2920 patients with cancers of the esophagus and esophagogastric junction: evaluation of the New Union Internationale Contre le Cancer/American Joint Cancer Committee staging system. Annals of surgery. 2011; 253:689-698.

4. Edge SB BD, Compton CC, Fritz AG, Greene FL. AJCC Cancer Staging Handbook: From the AJCC Cancer Staging New York. Springer. 2010.

5. Sobin LH GM. TNM classification of malignant tumors. (New York: Wiley Liss). 2010.

6. Reeh M, Nentwich MF, von Loga K, Schade J, Uzunoglu FG, Koenig AM, Bockhorn M, Rosch T, Izbicki JR, Bogoevski D. An attempt at validation of the Seventh edition of the classification by the International Union Against Cancer for esophageal carcinoma. The Annals of thoracic surgery. 2012; 93:890-896.

7. Siewert JR, Stein HJ, Feith M, Bruecher BL, Bartels H, Fink U. Histologic tumor type is an independent prognostic parameter in esophageal cancer: lessons from more than 1,000 consecutive resections at a single center in the Western world. Annals of surgery. 2001; 234:360-367; discussion 368-369.

8. Yuequan J, Shifeng C, Bing Z. Prognostic factors and family history for survival of esophageal squamous cell carcinoma patients after surgery. The Annals of thoracic surgery. 2010; 90:908-913.

9. Chen SB, Weng HR, Wang G, Yang JS, Yang WP, Liu DT, Chen YP, Zhang H. Prognostic factors and outcome for patients with esophageal squamous cell carcinoma underwent surgical resection alone: evaluation of the seventh edition of the American Joint Committee on Cancer staging system for esophageal squamous cell carcinoma. Journal of thoracic oncology. 2013; 8:495-501.

10. Liu J, Xie X, Zhou C, Peng S, Rao D, Fu J. Which factors are associated with actual 5-year survival of oesophageal squamous cell carcinoma? European journal of cardiothoracic surgery. 2012; 41:e7-11.

11. Iasonos A, Schrag D, Raj GV, Panageas KS. How to build and interpret a nomogram for cancer prognosis. Journal of clinical oncology. 2008; 26:1364-1370.
12. Balachandran VP, Gonen M, Smith JJ, DeMatteo RP. Nomograms in oncology: more than meets the eye. The Lancet Oncology. 2015; 16:e173-e180.

13. Valentini $\mathrm{V}$, van Stiphout $\mathrm{RG}$, Lammering $\mathrm{G}$, Gambacorta MA, Barba MC, Bebenek M, Bonnetain F, Bosset JF, Bujko K, Cionini L, Gerard JP, Rodel C, Sainato A, et al. Nomograms for predicting local recurrence, distant metastases, and overall survival for patients with locally advanced rectal cancer on the basis of European randomized clinical trials. Journal of clinical oncology. 2011; 29:3163-3172.

14. Han DS, Suh YS, Kong SH, Lee HJ, Choi Y, Aikou S, Sano T, Park BJ, Kim WH, Yang HK. Nomogram predicting long-term survival after $\mathrm{d} 2$ gastrectomy for gastric cancer. Journal of clinical oncology. 2012; 30:3834-3840.

15. Karakiewicz PI, Briganti A, Chun FK, Trinh QD, Perrotte P, Ficarra V, Cindolo L, De la Taille A, Tostain J, Mulders PF, Salomon L, Zigeuner R, Prayer-Galetti T, et al. Multiinstitutional validation of a new renal cancer-specific survival nomogram. Journal of clinical oncology. 2007; 25:1316-1322.

16. Zaak D, Burger M, Otto W, Bastian PJ, Denzinger S, Stief CG, Buchner H, Hartmann A, Wieland WF, Shariat SF, Fritsche HM. Predicting individual outcomes after radical cystectomy: an external validation of current nomograms. BJU international. 2010; 106:342-348.

17. Liang W, Zhang L, Jiang G, Wang Q, Liu L, Liu D, Wang Z, Zhu Z, Deng Q, Xiong X, Shao W, Shi X, He J. Development and validation of a nomogram for predicting survival in patients with resected non-small-cell lung cancer. Journal of clinical oncology. 2015; 33:861-869.

18. Wang Y, Li J, Xia Y, Gong R, Wang K, Yan Z, Wan X, Liu G, Wu D, Shi L, Lau W, Wu M, Shen F. Prognostic nomogram for intrahepatic cholangiocarcinoma after partial hepatectomy. Journal of clinical oncology. 2013; 31:1188-1195.

19. Rizk NP, Ishwaran H, Rice TW, Chen LQ, Schipper PH, Kesler KA, Law S, Lerut TE, Reed CE, Salo JA, Scott WJ, Hofstetter WL, Watson TJ, et al. Optimum lymphadenectomy for esophageal cancer. Annals of surgery. 2010; 251:46-50.

20. Edge SB, Compton CC. The American Joint Committee on Cancer: the 7th edition of the AJCC cancer staging manual and the future of TNM. Annals of surgical oncology. 2010; 17:1471-1474.

21. Sobin LH WC. TNM classification of malignant tumors. (New York: Wiley Liss). 2002.

22. Bollschweiler E, Baldus SE, Schroder W, Schneider PM, Holscher AH. Staging of esophageal carcinoma: length of tumor and number of involved regional lymph nodes. Are these independent prognostic factors? Journal of surgical oncology. 2006; 94:355-363.

23. Rizk N, Venkatraman E, Park B, Flores R, Bains MS, Rusch V. The prognostic importance of the number of 
involved lymph nodes in esophageal cancer: implications for revisions of the American Joint Committee on Cancer staging system. The Journal of thoracic and cardiovascular surgery. 2006; 132:1374-1381.

24. Hofstetter W, Correa AM, Bekele N, Ajani JA, Phan A, Komaki RR, Liao Z, Maru D, Wu TT, Mehran RJ, Rice DC, Roth JA, Vaporciyan AA, et al. Proposed modification of nodal status in AJCC esophageal cancer staging system. The Annals of thoracic surgery. 2007; 84:365-373; discussion 374-365.

25. Dhar DK, Hattori S, Tonomoto Y, Shimoda T, Kato H, Tachibana M, Matsuura K, Mitsumoto Y, Little AG, Nagasue N. Appraisal of a revised lymph node classification system for esophageal squamous cell cancer. The Annals of thoracic surgery. 2007; 83:1265-1272.

26. Bogoevski D, Onken F, Koenig A, Kaifi JT, Schurr P, Sauter G, Izbicki JR, Yekebas EF. Is it time for a new TNM classification in esophageal carcinoma? Annals of surgery. 2008; 247:633-641.

27. Lin CS, Chang SC, Wei YH, Chou TY, Wu YC, Lin HC, Wang LS, Hsu WH. Prognostic variables in thoracic esophageal squamous cell carcinoma. The Annals of thoracic surgery. 2009; 87:1056-1065.

28. Kayani B, Zacharakis E, Ahmed K, Hanna GB. Lymph node metastases and prognosis in oesophageal carcinoma-a systematic review. European journal of surgical oncology. 2011; 37:747-753.

29. Rice TW, Rusch VW, Apperson-Hansen C, Allen MS, Chen LQ, Hunter JG, Kesler KA, Law S, Lerut TE, Reed CE, Salo JA, Scott WJ, Swisher SG, et al. Worldwide esophageal cancer collaboration. Diseases of the esophagus. 2009; 22:1-8.

30. Greenstein AJ, Litle VR, Swanson SJ, Divino CM, Packer S, Wisnivesky JP. Effect of the number of lymph nodes sampled on postoperative survival of lymph nodenegative esophageal cancer. Cancer. 2008; 112:1239-1246.

31. $\mathrm{Hu} \mathrm{Y,} \mathrm{Hu} \mathrm{C,} \mathrm{Zhang} \mathrm{H,} \mathrm{Ping} \mathrm{Y,} \mathrm{Chen} \mathrm{LQ.} \mathrm{How} \mathrm{does} \mathrm{the}$ number of resected lymph nodes influence TNM staging and prognosis for esophageal carcinoma? Annals of surgical oncology. 2010; 17:784-790.

32. Peyre CG, Hagen JA, DeMeester SR, Altorki NK, Ancona E, Griffin SM, Holscher A, Lerut T, Law S, Rice TW, Ruol A, van Lanschot JJ, Wong J, et al. The number of lymph nodes removed predicts survival in esophageal cancer: an international study on the impact of extent of surgical resection. Annals of surgery. 2008; 248:549-556.

33. Altorki NK, Zhou XK, Stiles B, Port JL, Paul S, Lee PC, Mazumdar M. Total number of resected lymph nodes predicts survival in esophageal cancer. Annals of surgery. 2008; 248:221-226.

34. Schwarz RE, Smith DD. Clinical impact of lymphadenectomy extent in resectable esophageal cancer. Journal of gastrointestinal surgery. 2007; 11:1384-1393; discussion 1393-1384.
35. Groth SS, Virnig BA, Whitson BA, DeFor TE, Li ZZ, Tuttle TM, Maddaus MA. Determination of the minimum number of lymph nodes to examine to maximize survival in patients with esophageal carcinoma: data from the Surveillance Epidemiology and End Results database. The Journal of thoracic and cardiovascular surgery. 2010; 139:612-620.

36. Liu YP, Ma L, Wang SJ, Chen YN, Wu GX, Han M, Wang XL. Prognostic value of lymph node metastases and lymph node ratio in esophageal squamous cell carcinoma. European journal of surgical oncology. 2010; 36:155-159.

37. Kelty CJ, Kennedy CW, Falk GL. Ratio of metastatic lymph nodes to total number of nodes resected is prognostic for survival in esophageal carcinoma. Journal of thoracic oncology. 2010; 5:1467-1471.

38. Hsu WH, Hsu PK, Hsieh CC, Huang CS, Wu YC. The metastatic lymph node number and ratio are independent prognostic factors in esophageal cancer. Journal of gastrointestinal surgery. 2009; 13:1913-1920.

39. Wijnhoven BP, Tran KT, Esterman A, Watson DI, Tilanus HW. An evaluation of prognostic factors and tumor staging of resected carcinoma of the esophagus. Annals of surgery. 2007; 245:717-725.

40. Wilson M, Rosato EL, Chojnacki KA, Chervoneva I, Kairys JC, Cohn HE, Rosato FE, Sr., Berger AC. Prognostic significance of lymph node metastases and ratio in esophageal cancer. The Journal of surgical research. 2008; 146:11-15.

41. Espin F, Bianchi A, Llorca S, Feliu J, Palomera E, Garcia O, Remon J, Sunol X. Metastatic lymph node ratio versus number of metastatic lymph nodes as a prognostic factor in gastric cancer. European journal of surgical oncology. 2012; 38:497-502.

42. Lemmens VE, Dassen AE, van der Wurff AA, Coebergh JW, Bosscha K. Lymph node examination among patients with gastric cancer: variation between departments of pathology and prognostic impact of lymph node ratio. European journal of surgical oncology. 2011; 37:488-496.

43. Danko ME, Bennett KM, Zhai J, Marks JR, Olson JA Jr, Improved staging in node-positive breast cancer patients using lymph node ratio: results in 1,788 patients with long-term follow-up. Journal of the American College of Surgeons. 2010; 210:797-805 e791, 805-797.

44. Taylor MD, Lapar DJ, Thomas CJ, Persinger M, Stelow EB, Kozower BD, Lau CL, Jones DR. Lymph node ratio predicts recurrence and survival after $\mathrm{R} 0$ resection for non-small cell lung cancer. The Annals of thoracic surgery. 2013; 96:1163-1170.

45. Lyu X, Huang J, Mao Y, Liu Y, Feng Q, Shao K, Gao S, Jiang Y, Wang J, He J. Adjuvant chemotherapy after esophagectomy: is there a role in the treatment of the lymph node positive thoracic esophageal squamous cell carcinoma? Journal of surgical oncology. 2014; 110:864-868. 
46. Rice TW, Adelstein DJ, Chidel MA, Rybicki LA, DeCamp MM, Murthy SC, Blackstone EH. Benefit of postoperative adjuvant chemoradiotherapy in locoregionally advanced esophageal carcinoma. The Journal of thoracic and cardiovascular surgery. 2003; 126:1590-1596.

47. Bedard EL, Inculet RI, Malthaner RA, Brecevic E, Vincent M, Dar R. The role of surgery and postoperative chemoradiation therapy in patients with lymph node positive esophageal carcinoma. Cancer. 2001; 91:2423-2430.

48. Hsu PK, Huang CS, Wang BY, Wu YC, Hsu WH. Survival benefits of postoperative chemoradiation for lymph nodepositive esophageal squamous cell carcinoma. The Annals of thoracic surgery. 2014; 97:1734-1741.

49. Chen J, Pan J, Liu J, Li J, Zhu K, Zheng X, Chen M, Chen M, Liao Z. Postoperative radiation therapy with or without concurrent chemotherapy for node-positive thoracic esophageal squamous cell carcinoma. International journal of radiation oncology, biology, physics. 2013; 86:671-677.

50. Xiao ZF, Yang ZY, Miao YJ, Wang LH, Yin WB, Gu XZ, Zhang DC, Sun KL, Chen GY, He J. Influence of number of metastatic lymph nodes on survival of curative resected thoracic esophageal cancer patients and value of radiotherapy: report of 549 cases. International journal of radiation oncology, biology, physics. 2005; 62:82-90.

51. Xiao ZF, Yang ZY, Liang J, Miao YJ, Wang M, Yin WB, Gu XZ, Zhang DC, Zhang RG, Wang LJ. Value of radiotherapy after radical surgery for esophageal carcinoma: a report of 495 patients. The Annals of thoracic surgery. 2003; 75:331-336.

52. Teniere P, Hay JM, Fingerhut A, Fagniez PL. Postoperative radiation therapy does not increase survival after curative resection for squamous cell carcinoma of the middle and lower esophagus as shown by a multicenter controlled trial. French University Association for Surgical Research. Surg Gynecol Obstet. 1991; 173:123-130.
53. Fok M, Sham JS, Choy D, Cheng SW, Wong J. Postoperative radiotherapy for carcinoma of the esophagus: a prospective, randomized controlled study. Surgery. 1993; 113:138-147.

54. Lin SH, Wang L, Myles B, Thall PF, Hofstetter WL, Swisher SG, Ajani JA, Cox JD, Komaki R, Liao Z. Propensity score-based comparison of long-term outcomes with 3-dimensional conformal radiotherapy vs intensitymodulated radiotherapy for esophageal cancer. International journal of radiation oncology, biology, physics. 2012; 84:1078-1085.

55. Liu HC, Hung SK, Huang CJ, Chen CC, Chen MJ, Chang CC, Tai CJ, Tzen CY, Lu LH, Chen YJ. Esophagectomy for locally advanced esophageal cancer, followed by chemoradiotherapy and adjuvant chemotherapy. World J Gastroenterol. 2005; 11:5367-5372.

56. Zhang W, Zhu H, Liu X, Wang Q, Zhang X, He J, Sun K, Liu X, Zhou Z, Xu N, Xiao Z. Epidermal growth factor receptor is a prognosis predictor in patients with esophageal squamous cell carcinoma. The Annals of thoracic surgery. 2014; 98:513-519.

57. Chan DS, Reid TD, Howell I, Lewis WG. Systematic review and meta-analysis of the influence of circumferential resection margin involvement on survival in patients with operable oesophageal cancer. The British journal of surgery. $2013 ; 100: 456-464$.

58. Harrell FE, Jr., Califf RM, Pryor DB, Lee KL and Rosati RA. Evaluating the yield of medical tests. Jama. 1982; 247:2543-2546.

59. Therneau TMA EJ. An Introduction to Recursive Partitioning Using the RPART Routine. Mayo Clinic, Rochester, MN. 1997. 